\title{
Avaliação do Sinergismo Entre Extratos de Anadenanthera colubrina (Angico) e Antibióticos de Referência Frente A Isolados Clínicos de Staphylococcus aureus Resistente À Meticilina (MRSA)
}

Pérola Paloma Silva do Nascimento (I), Rafaela de Siqueira Ferraz Carvalho (II), Thaís Soares da Silva (I), Thiago Antônio de Sousa Araújo (II), Elba Lucia Cavalcanti de Amorim (II), Isabella Macário Ferro Cavalcanti $(\mathrm{I}, \mathrm{II})$

(I) UFPE - Universidade Federal de Pernambuco (Rua do Alto do Reservatório s/n, Bela Vista, 55608-680, Vitória de Santo Antão ), (II) UFPE - Universidade Federal de Pernambuco (Av.

Prof. Moraes Rego, 1235 - Cidade Universitária, 50670-901, Recife, PE)

\section{Resumo}

Introdução: O surgimento e disseminação de bactérias multirresistentes consistem em relevantes problemas de saúde pública. Neste contexto, infecções ocasionadas por Staphylococcus aureus resistentes à meticilina (MRSA) podem apresentar elevada morbimortalidade. Nesse âmbito, a comunidade científica tem empreendido esforços para desenvolver ou descobrir novas classes de antibióticos, assim como propor o sinergismo entre moléculas. Desta forma, o objetivo deste estudo consistiu em avaliar o sinergismo entre extratos da casca de Anadenanthera colubrina (angico) e antibióticos de referência frente a isolados clínicos de MRSA. Material e Métodos: Inicialmente foram preparados extratos da casca de seis indivíduos de A. colubrina que apresentaram áreas de casca regenerada após ação extrativista. De cada um destes indivíduos foram coletadas duas amostras, sendo uma de tecido intacto e outra de tecido regenerado totalizando 12 amostras. Para a avaliação da atividade antimicrobiana destes extratos frente à MRSA foi determinada a concentração inibitória

\footnotetext{
Referência:

Pérola Paloma Silva do Nascimento, Rafaela de Siqueira Ferraz Carvalho, Thaís Soares da Silva, Thiago Antônio de Sousa Araújo, Elba Lucia Cavalcanti de Amorim, Isabella Macário Ferro Cavalcanti. Avaliação do Sinergismo Entre Extratos de Anadenanthera Colubrina (Angico) e Antibióticos de Referência Frente A Isolados Clínicos de Staphylococcus Aureus Resistente À Meticilina (MRSA). In: Anais do 12 Congresso Latinoamericano de Microbiologia e Higiene de Alimentos - MICROAL 2014 [= Blucher Food Science Proceedings, num.1, vol.1]. São Paulo: Editora Blucher, 2014. 
mínima (CIM) e a concentração bactericida mínima (CBM) pelo método da microdiluição em caldo de acordo com o Clinical and Laboratory Standards Institute (CLSI). Para avaliar o sinergismo entre os extratos e os fármacos de referência (ciprofloxacina e eritromicina) foi utilizado o método checkerboard. Resultados e Discussão: Todos os extratos de angico apresentaram atividade bacteriostática (CIM $=8-32 \mu \mathrm{g} / \mathrm{mL}$ ) frente aos dez isolados clínicos de MRSA, porém nenhum deles apresentou efeito bactericida $(\mathrm{CBM}>250 \mu \mathrm{g} / \mathrm{mL})$. Adicionalmente, não houve diferença nos valores de CIM e CBM entre os extratos obtidos a partir das cascas intactas ou regeneradas, sugerindo que mesmo após a regeneração, as cascas desta espécie apresentam a mesma atividade antimicrobiana. Os resultados obtidos sugerem que a interação in vitro entre a maioria dos extratos de Anadenanthera colubrina e ciprofloxacina ou eritromicina é do tipo aditiva $(\mathrm{FICI}=0,52)$, porém um dos extratos apresentou interação sinérgica com os fármacos padrões (FICI $=0,27$ ). Conclusão: Desta forma, o angico parece ser uma alternativa para o tratamento de infecções provocadas pelo S. aureus resistente à meticilina, além disso, a combinação destes extratos com ciprofloxacina e eritromicina age aditivamente ou sinergicamente frente à MRSA.

Palavras-Chave: Anadenanthera colubrina, Angico, Atividade antibacteriana, Extrato, MRSA

\section{Agência de Fomento:}

